\title{
POLINIZAÇÃO CONTROLADA EM Araucaria angustifolia
}

\author{
Justina Inês Anselmini ${ }^{1}$, Flávio Zanette ${ }^{2}$
}

(recebido: 19 de julho de 2010; aceito: 22 de dezembro de 2011)

\begin{abstract}
RESUMO: Neste trabalho, objetivou-se determinar uma metodologia para polinização controlada em Araucaria angustifolia, visando ao melhoramento genético da espécie e o aumento da produção de pinhões, por meio do manejo com polinizações suplementares. Para tanto, foi desenvolvida uma metodologia de polinização controlada por meio de vários experimentos realizados entre 2003 e 2005. Foram avaliados os efeitos da polinização controlada, da quantidade de pólen aplicada por ginostróbilo, a época de polinização e o estádio de desenvolvimento do ginostróbilo durante a polinização sobre o número de pinhões produzidos por pinha. Uma única polinização controlada resulta em baixa produção de pinhões cheios e a polinização em estádios mais avançados de desenvolvimento do ginostróbilo resulta em valores elevados de pinhões cheios por pinha. A polinização controlada em A. angustifolia é efetiva para a produção de pinhões e a sua aplicação em cruzamentos dirigidos permitirá que cruzamentos, hoje impossíveis na natureza pela grande distância entre os pais, possam ocorrer. A polinização controlada realizada duas vezes nos ginostróbilos com mais de 30 mm de diâmetro aumenta a produção de pinhões por pinha.
\end{abstract}

Palavras-chave: Pólen, ginostróbilos, pinhões, pinhas.

\section{CONTROLLED POLLINATION IN Araucaria angustifolia}

ABSTRACT: The objective of this study was to develop a methodology for controlled pollination of Araucaria angustifolia, aiming at the genetic improvement of the species and increased yield of pine nuts through management with supplemental pollination. A methodology of controlled pollination was developed in which several experiments were carried out in 2003-2005 period. The effects of the following parameters were evaluated: controlled pollination, amount of pollen applied per female strobilus, time of pollination, and development stage of the female strobilus during pollination on the number of pine nuts yielded per pine cone. A single controlled pollination procedure results in low yield of fully filled pine nuts, and pollination at later development stages of the female strobilus results in high yields of fully filled pine nuts per pine cone. Controlled pollination in A. angustifolia proved effective for pine nut production and its application in oriented breeding procedures will enable breeding that up until now was considered impossible in nature on account of the considerable distance between the parent plants. Controlled pollination performed twice in female strobili more than $30 \mathrm{~mm}$ in diameter does increase the yield of pine nuts per pine cone.

Key words: Pollen, female strobili, pine nuts, pine cones.

\section{INTRODUÇÃO}

A exploração tradicional da A. angustifolia, principalmente para a produção de madeira, destruiu grande parte da Floresta com Araucária. Do imenso território ocupado por este tipo de vegetação restam, atualmente, pequenos remanescentes isolados geograficamente. Grande parte da variabilidade genética dessa espécie foi perdida e em decorrência da distância entre os remanescentes, o fluxo gênico foi interrompido ou severamente limitado (SOUSA, 2000).

A atual legislação impede a exploração da $A$. angustifolia no intuito de impedir à derrubada das árvores. A comercialização dos pinhões pode ser uma alternativa para aqueles que plantaram ou possuem áreas com araucária e que hoje consideram essa espécie um entrave ao desenvolvimento da sua propriedade. A utilização de práticas de manejo na $A$. angustifolia, visando ao aumento na produção de pinhas, pode tornar o pinhão uma fonte de renda anual, com retorno econômico para as áreas plantadas com araucária.

Um anseio da sociedade é a manutenção da Floresta com Araucária, pois a exploração do pinhão pode impedir a regeneração natural da floresta. Para tanto, existe a necessidade de orientação e de normatização da exploração do pinhão, com uma estrutura física e humana comprometida em realizar um trabalho sério e efetivo e que possa resultar em retorno econômico para aqueles que plantam essa espécie com o propósito de produção de pinhões e impedir a exploração extrativista nas populações naturais. O desenvolvimento de um sistema de certificação sócioambiental do pinhão pode também contribuir para

\footnotetext{
${ }^{1}$ Bióloga, Doutora em Agronomia pela Universidade Federal do Paraná/UFPR - Rua dos Funcionários, 1540, Juvevê - Cx. P. 19061 - 80035050 Curitiba, PR, Brasil - justinaines@pop.com.br

${ }^{2}$ Engenheiro Agrônomo, Professor Doutor em Fitotecnia - Departamento de Fitotecnia e Fitossanitarismo - Universidade Federal do Paraná/UFPR Rua dos Funcionários, 1540, Juvevê - Cx. P. 19061 -80035050 - Curitiba, PR, Brasil - flazan@ufpr.br
}

Cerne, Lavras, v. 18, n. 2, p. 247-255, abr./jun. 2012 
valorizá-lo como produto especializado para mercados mais valorizados. Além da inclusão do pinhão nos programas de combate a fome, para valorização da cultura (FLORIANI, 2007).

O consumo do pinhão e a expansão deste mercado ainda são muito afetados pela sazonalidade da sua produção, que se restringe a alguns meses do ano. $\mathrm{O}$ pinhão, como alimento, não possui estudos suficientes que possibilitem a sua industrialização e a sua comercialização é feita de maneira desorganizada, impedindo a sua disponibilidade nas regiões não produtoras de pinhão.

Estados tipicamente agrícolas como o Paraná, medidas de incentivo à recuperação de áreas florestais são mais eficientes quando refletem sobre a economia do agricultor, assim, a conservação das Florestas com Araucária deve estar apoiada na preservação integral e no uso sustentável da área de preservação (PIRES, 2003).

O conhecimento da biologia reprodutiva é fundamental para garantir a produção de semente melhorada nos pomares de semente, que constituem parte fundamental de programas de melhoramento genético de espécies florestais e promover por técnicas de propagação vegetativa a precocidade de produção nas mudas.

Em populações de campo, com baixa densidade de plantas, a produção de estróbilos por planta é maior do que nos remanescentes florestais (MANTOVANI et al., 2004), possivelmente pela menor disputa por luz e nutrientes do solo. À distância entre as plantas também favorece a permanência dos verticilos basais por mais tempo na planta, pois não há o atrito e choques mecânicos com galhos das plantas vizinhas como ocorre na floresta fechada. Nesse sentido, a produção de pinhões pode ser aumentada com práticas de manejo simples, pois o controle do ambiente é um fator primordial para que a árvore cresça e produza de maneira desejada. Dessa forma, o manejo que se deseja difundir para os plantios de $A$. angustifolia que visam à produção de pinhões é o maior espaçamento entre as árvores e manutenção do maior número de verticilos vegetativos por árvore, sem desbaste de ramos, visando a aumentar a capacidade reprodutiva. Como há um forte controle ambiental da floração (POWELL, 1977), a manipulação florestal com manutenção de menor número de árvores por hectare pode tornar-se dispendiosa em grandes plantios, no entanto, pode ser justificada economicamente em pomares produtores de sementes.

A polinização controlada pode ser uma importante ferramenta no melhoramento genético (INSTITUTO DE
PESQUISAS E ESTUDOS FLORESTAIS - IPEF, 1977), pois os pinhões formados podem apresentar elevado grau de heterose, o que favorece a identificação e seleção de progênies que possuam características de importância como alta produtividade e maior capacidade de adaptação a condições ambientais distintas (BRIGATTI et al., 1983).

Nesse sentido, conduziu-se este trabalho, com o objetivo de determinar uma metodologia de polinização controlada em A. angustifolia, visando a dar subsídios a trabalhos futuros de melhoramento genético da espécie e o aumento da produção de pinhões pelo manejo com polinizações suplementares.

\section{MATERIAL E MÉTODOS}

No ano de 2003, foram iniciados os experimentos com polinização controlada em A. angustifolia. Foram utilizadas plantas adultas em fase reprodutiva, todas identificadas e localizadas no Campus do Setor de Ciências Agrárias da UFPR.

\subsection{Efeito da polinização controlada no número de pinhões produzidos por pinha}

Para esse propósito, foram selecionadas três plantas femininas e uma masculina. O delineamento foi o inteiramente casualizado com os tratamentos em arranjo fatorial $3 \times 2$, sendo três plantas matrizes e dois tratamentos de polinização (testemunhas com polinização aberta e polinizadas artificialmente). Cada tratamento foi composto por quatro repetições, com uma pinha por unidade experimental.

No mês de agosto, com o auxílio de caminhão equipado com plataforma elevatória, foram isolados com sacos plásticos, ginostróbilos, ainda fechados, nas plantas femininas selecionadas. $\mathrm{O}$ isolamento foi realizado para evitar a contaminação com pólen de outras plantas e retirado somente após o término do período de polinização.

O pólen utilizado foi coletado dos androstróbilos no dia de cada polinização. O pólen foi retirado, peneirado e depositado em pissete com bico para aspersão sobre o ginostróbilo.

No período de polinização, setembro e outubro, quando os ginostróbilos estavam abertos, o isolamento foi retirado e feita uma polinização manual com o pólen retirado do macho selecionado. As pinhas testemunhas não sofreram esse tratamento, sendo apenas identificadas com etiquetas.

Cerne, Lavras, v. 18, n. 2, p. 247-255, abr./jun. 2012 
As pinhas polinizadas e as testemunhas foram colhidas de abril a julho de 2005.

No mês de janeiro, foram selecionados dez ramos de cada matriz, sendo cinco ramos com pinhas tratadas e cinco com pinhas testemunhas. Nesses ramos, foi realizada uma contagem do número de pinhas necrosadas em relação ao número de pinhas sadias. Foram utilizadas quatro matrizes que sofreram os tratamentos de polinização controlada. Os dados foram transformados em porcentagem de pinhas necrosadas para pinhas tratadas e testemunhas nas quatro matrizes.

\subsection{Efeito da quantidade de pólen utilizado na polinização controlada sobre o número de pinhões produzidos por pinha}

Para esse propósito, foram realizados nos anos de 2003 e 2004 experimentos com variação na quantidade de pólen aspergido sobre as pinhas isoladas. $\mathrm{O}$ isolamento ocorreu no mês de agosto e setembro e a polinização foi realizada no mês de outubro.

O experimento foi realizado em apenas uma planta matriz, com delineamento inteiramente casualizado em arranjo fatorial 2x4, sendo dois anos de polinização (2003 e 2004) e quatro tratamentos: aberta),

- Testemunhas (não isoladas e sujeitas à polinização

- Pinhas isoladas seguidas de uma única polinização (1,1 g de pólen),

- Pinhas isoladas seguidas de uma única polinização com excesso de pólen (3,3 g de pólen),

- Pinhas isoladas sem polinização.

Cada tratamento foi composto por cinco repetições, com uma pinha por unidade experimental. Nas pinhas polinizadas artificialmente, foram realizados os mesmos processos de isolamento e polinização descritos no item anterior.

As pinhas polinizadas e as testemunhas foram colhidas em abril de 2005 e 2006.

\subsection{Efeito da época de polinização e do estádio de} desenvolvimento do ginostróbilo sobre o número de pinhões produzidos por pinha

No ano de 2004, realizou-se um experimento para avaliar o estádio de desenvolvimento do ginostróbilo durante a polinização controlada, com o objetivo de determinar o estádio mais apropriado para a polinização controlada e com maior produção de pinhões por pinha.

Para isso, foram isolados ginostróbilos fechados no mês de agosto numa planta selecionada, e durante o período de polinização (setembro e outubro) foram realizadas polinizações controladas em diferentes estádios de desenvolvimento do ginostróbilo.

O experimento foi inteiramente casualizado com quatro tratamentos:

- Testemunhas sem isolamento e polinização aberta;

- Ginostróbilos abrindo (menos de $30 \mathrm{~mm}$ de diâmetro);

- Ginostróbilos abertos (de 30 a $40 \mathrm{~mm}$ de diâmetro);

- Ginostróbilos abertos (mais de $40 \mathrm{~mm}$ de diâmetro).

Cada tratamento foi composto por cinco repetições, com uma pinha por unidade experimental.

Nas pinhas polinizadas artificialmente foram realizados os mesmos processos de isolamento e polinização descritos anteriormente. A polinização foi única e de acordo com o estádio do ginostróbilo que se desejava testar.

As pinhas polinizadas e as testemunhas foram colhidas em abril de 2006.

\subsection{Efeito de polinizações seguidas em ginostróbilos sobre o número de pinhões por pinha}

Como foi observado que nos anos anteriores as pinhas que sofreram polinização controlada tiveram uma redução no número de pinhões por pinha, houve a necessidade de melhorar a técnica, para aumentar a produtividade. Para isso, no ano de 2005, foi realizado um experimento com polinizações consecutivas.

$\mathrm{O}$ experimento foi inteiramente casualizado em arranjo fatorial $2 \times 3$, sendo duas plantas matrizes e três tratamentos ( 1 polinização, 2 polinizações e 3 polinizações semanais consecutivas). Na primeira semana, todos os ginostróbilos foram polinizados, na segunda semana, apenas os do $2^{\circ}$ e $3^{\circ}$ tratamento e na terceira semana apenas os do $3^{\circ}$ tratamento. Cada tratamento constou de cinco repetições com uma pinha por unidade experimental.

As pinhas produzidas foram colhidas em abril e maio de 2007.

Para todos os experimentos, após a colheita das pinhas foram avaliados o número total de pinhões (cheios + chochos) e a porcentagem de pinhões cheios em relação aos chochos. Os dados coletados foram analisados pela análise de variância e as médias comparadas pelo Teste de Tukey ao nível de 5\% de probabilidade. O programa estatístico utilizado foi o MSTAT (MICHIGAN STATE UNIVERSITY, 1991).

Cerne, Lavras, v. 18, n. 2, p. 247-255, abr./jun. 2012 


\section{RESULTADOS E DISCUSSÃO}

\subsection{Efeito da polinização controlada no número de pinhões produzidos por pinha}

O teste de Tukey revelou diferenças significativas nas médias do número total de pinhões (cheios + chochos) entre as plantas matrizes avaliadas, indicando que a capacidade produtiva das pinhas é variável com relação à planta mãe (Tabela 1). Diferenças na massa das sementes e no número de sementes por pinha também foram descritas por Mantovani et al. (2004), indicando o efeito da planta sobre essas características. No entanto, a massa das sementes e o número de sementes por pinha são homogêneos dentro da planta. De acordo com Carvalho (1994), os ginostróbilos podem variar quanto à quantidade de sementes, de 5 a 150 sementes produzidas por pinha, sendo que a massa pode chegar a $4,7 \mathrm{Kg}$ de cada pinha.

Tabela 1 - Média do número de pinhões (cheios + chochos) de pinhas provenientes de polinização controlada e aberta, colhidas em 2005, em três matrizes de A. angustifolia.

Table 1-Mean number of pine nuts (fully filled + hollow) yielded by pine cones subjected to controlled and open pollination, harvested in 2005, in three matrix plants of A. angustifolia.

\begin{tabular}{lc}
\hline Matrizes & Média de pinhões (cheios + chochos) \\
\hline 1 & $147,3 \mathrm{a}$ \\
2 & $157,7 \mathrm{a}$ \\
3 & $104,7 \mathrm{~b}$ \\
\hline Tipo de polinização & \\
\hline Aberta & $141,0 \mathrm{a}$ \\
Controlada & $132,0 \mathrm{a}$ \\
\hline CV $(\%)$ & 16,1 \\
\hline
\end{tabular}

Médias não seguidas de mesma letra minúscula na coluna diferem significativamente pelo Teste de Tukey, em nível de 5\% de probabilidade de erro.

Means not followed by the same small letter in a column differ significantly by the Tukey test, at the 5\% error probability level.

Algumas plantas apresentam pinhas nos ramos primários e secundários (ANSELMINI et al., 2006), o que pode aumentar a capacidade produtiva dessas plantas por conter um elevado número de pinhas por ramo. No entanto, as pinhas dos ramos secundários são menores que as dos ramos primários, e isso pode refletir na capacidade produtiva da pinha, com um número de óvulos disponíveis para a fecundação menor do que nas pinhas de ramos primários. A matriz 3 utilizada é um exemplo de planta com grande produtividade por apresentar pinhas nos dois tipos de ramos, mas a capacidade de produção de pinhões por pinha foi menor do que nas duas outras plantas testadas, que não possuíam pinhas nos ramos secundários.

Em relação ao número total de pinhões produzidos por pinhas polinizadas artificialmente e testemunhas, as médias foram estatisticamente semelhantes, o que demonstra que a capacidade produtiva máxima das pinhas é um fator determinado pela planta mãe (genético ou fisiológico), mesmo com disponibilidade de pólen. $\mathrm{O}$ número de folhas modificadas com óvulos na sua base é determinado no início da formação da pinha, antes do período de polinização, o que pode variar posteriormente é o número de pinhões cheios, que foram fecundados e o número de pinhões chochos que não foram fecundados. A distância entre as plantas masculinas e femininas está diretamente relacionada ao número de pinhões cheios por pinha. Quanto maior a proximidade entre essas plantas maior a disponibilidade de pólen para os ginostróbilos. Outro fator que pode influenciar na disponibilidade de pólen é a precocidade de abertura do ginostróbilo. Como já descrito por Anselmini et al. (2006), algumas plantas apresentam abertura do ginostróbilo precoce, logo no início do período de polinização e outras mais tardia. As plantas femininas que apresentam abertura do ginostróbilo precoce, logo no início do período de polinização, mas estão próximas a plantas masculinas que têm liberação do pólen tardia, possuirão menor disponibilidade de pólen e consequente menor número de pinhões cheios.

O padrão de floração e frutificação em espécies florestais é muito irregular e imprevisível e a produção de frutos e sementes varia não apenas entre as espécies, mas também entre as árvores da mesma espécie e de ano para ano na mesma árvore (KRAMER; KOZLOWSKI, 1979).

A partir do ano de 2003, início dos experimentos com polinização controlada, foi observada a necrose de uma porcentagem significativa das pinhas, tanto tratadas como testemunhas, que ocorre de um a dois meses após a polinização, com uma perda significativa de pinhas, após esse período crítico, embora, não se tenha observado mais a ocorrência da necrose nas pinhas restantes.

A necrose das pinhas variou entre plantas e entre os dois tratamentos, mas nas pinhas polinizadas artificialmente a média de necrose foi igual ou inferior ao das pinhas testemunhas. A média geral de necrose nas pinhas polinizadas artificialmente foi de $36 \%$ e nas testemunhas $42 \%$. A utilização de isolamento plástico, nas pinhas tratadas poderia aumentar a umidade e a temperatura no local da pinha, favorecendo a proliferação

Cerne, Lavras, v. 18, n. 2, p. 247-255, abr./jun. 2012 
de fungos ou outros patógenos. No entanto, os dados comprovam que o tratamento com polinização controlada não interferiu aumentando a média de necrose.

A causa da necrose das pinhas não foi identificada, podendo ser resultado da presença de patógenos ou de fatores biológicos da própria planta, como disponibilidade de nutrientes e de fatores ambientais, como pluviosidade e temperatura. Conforme Smith e Hinckley (1995), as estruturas reprodutivas são responsáveis pelo consumo de 6 a $10 \%$ do produto fotossintético produzido e muitas espécies produzem mais estruturas reprodutivas no início do ciclo reprodutivo, e durante esse período pode ocorrer o aborto de parte dessas estruturas, diminuindo a porcentagem de frutos e sementes que chegam a maturação. O aborto de flores ou estróbilos é resultado da presença de condições ambientais adversas que restringem a assimilação de carbono, ou como sugerido por Powell (1977), uma grande produção de pinhas reduz a produção do ano seguinte, porque há um grande consumo de carbono pelas pinhas em desenvolvimento que inibe a indução de verticilos laterais e o seu crescimento.

De acordo com Mantovani et al. (2004), nas plantas femininas foram encontradas diferenças significativas entre os anos no número de ginostróbilos produzidos por planta. A sazonalidade de produção de pinhões entre anos, já citada por outros autores (MANTOVANI et al., 2004; SOUSA, 2000), pode ser resultante de um maior ou menor índice de pinhas necrosadas nos diferentes anos, por polinização deficiente ou por clima desfavorável (chuvas intermitentes).

Em relação à porcentagem de pinhões cheios e chochos por pinhas, houve interação entre os dois fatores testados, matrizes e tipo de polinização. Em relação ao número de pinhões cheios, tanto a matriz 1 como a 2 apresentaram maior número de pinhões cheios na polinização aberta, já, na matriz 3 , não se apresentou diferença entre as duas médias (Tabela 2). Na polinização aberta, as matrizes diferiram entre si, com maior média na matriz 1. Na polinização controlada, as matrizes 1 e 2 também apresentaram maior número de pinhões cheios do que na matriz 3.

O resultado obtido nas pinhas testemunhas está relacionado à disponibilidade de pólen vindo de machos próximos. Nesse sentido, pode-se concluir que a matriz 1 e 2, além de possuírem pinhas com capacidade produtiva maior, estão localizadas próximas a plantas masculinas com maior disponibilidade de pólen, o que possibilitou a produção de maior número de pinhões cheios e menor número de pinhões chochos.
Tabela 2 - Porcentagem média de pinhões cheios e chochos de pinhas provenientes de polinização controlada e aberta, em três matrizes de A. angustifolia, colhidas em 2005.

Table 2 - Mean percentage of fully filled and hollow pine nuts yielded by pine cones subjected to controlled and open pollination, in three matrix plants of A. angustifolia, harvested in 2005.

\begin{tabular}{|c|c|c|c|c|}
\hline \multirow{3}{*}{ Matrizes } & \multicolumn{2}{|c|}{ Pinhões cheios (\%) } & \multicolumn{2}{|c|}{ Pinhões chochos (\%) } \\
\hline & \multicolumn{2}{|c|}{ Tipo de polinização } & \multicolumn{2}{|c|}{ Tipo de polinização } \\
\hline & aberta & controlada & aberta & controlada \\
\hline 1 & 72,5 a & 35,5 a & $27,5 \mathrm{c}$ & $64,5 \mathrm{~b}$ \\
\hline 2 & $47,2 \mathrm{~b}$ & 32,0 a & $52,7 \mathrm{~b}$ & $68,0 \mathrm{~b}$ \\
\hline 3 & $9,5 \mathrm{c}$ & $7,5 \mathrm{~b}$ & 90,5 a & 92,2 a \\
\hline C V $(\%)$ & \multicolumn{2}{|c|}{16,5} & \multicolumn{2}{|c|}{9,50} \\
\hline
\end{tabular}

Médias não seguidas de mesma letra minúscula na coluna diferem significativamente pelo Teste de Tukey, em nível de $5 \%$ de probabilidade de erro.

Means not followed by the same small letter in a column differ significantly by the Tukey test, at the 5\% error probability level.

Na polinização controlada, tanto para pinhões cheios e chochos, as pinhas das matrizes 1 e 2 apresentaram médias elevadas em relação a matriz 3 . Além da capacidade produtiva das pinhas, a disponibilidade de pólen vai influenciar no número final de pinhões cheios. Nas pinhas polinizadas artificialmente, apesar da quantidade de pólen aplicada por pinha ter sido muito maior do que ocorreria naturalmente, o pólen foi aplicado uma única vez, enquanto que nas pinhas testemunhas a disponibilidade de pólen pode ter sido diária e por um período de quase dois meses, correspondente ao período de polinização, e que pode ter resultado numa produção maior.

O menor número de pinhões cheios obtidos das pinhas provenientes de polinização artificial demonstra que a técnica ainda não está adequada, necessitando de ajuste como a identificação do melhor período para a polinização ou polinizações consecutivas.

Não há trabalhos registrados de polinização controlada dentro da espécie, mas Tesdorff (1956) obteve híbridos interespecíficos em $A$. angustifolia, polinizada com pólen de Araucaria araucana e obteve pinhas com média de 2 a 3 pinhões. $O$ autor sugere a diminuição da capacidade germinativa do pólen armazenado por mais de dez meses como o fator causador dessa baixa produtividade. O que não foi o caso em nossos experimentos, pois o pólen utilizado foi colhido no mesmo dia da aplicação.

Cerne, Lavras, v. 18, n. 2, p. 247-255, abr./jun. 2012 


\subsection{Efeito da quantidade de pólen utilizado na polinização controlada sobre o número de pinhões produzidos por pinha}

Em relação ao número total de pinhões, não ocorreu interação entre os dois fatores testados. No entanto, houve diferenças significativas entre os dois anos avaliados, com maior número de pinhões para o ano de 2003 (Tabela 3). Isso indica que a capacidade produtiva das pinhas é variável entre plantas, mas também pode variar entre safras numa mesma planta. A formação das pinhas, que inicia nove meses antes da polinização (ANSELMINI et al., 2006), pode ser afetada por fatores ambientais e nutricionais da planta, podendo resultar em maior ou menor número de óvulos formados.

O número total de pinhões por pinhas também foi variável entre os quatro tratamentos testados (Tabela $3)$. As testemunhas com maior número de pinhões (cheios + chochos) por pinha diferiram das polinizadas artificialmente com única polinização. Essa diferença observada foi resultado da utilização de pinhas de ramos primários e secundários nos diferentes tratamentos, que possuem capacidade produtiva diferente. O tratamento com polinização controlada com única polinização, pode ter sido aplicado em mais pinhas de ramos secundários do que pinhas de ramos primários, diminuindo a sua média total de pinhões.

$\mathrm{O}$ efeito dos tratamentos é mais bem visualizado quando se compara o número de pinhões cheios em relação ao número de pinhões chochos. Nesse caso houve interação dos dois fatores testados, ano de polinização e tratamentos de polinização (Tabela 4).

Tabela 3 - Média do número total de pinhões (cheios + chochos), de pinhas provenientes de polinização controlada e aberta, com variação na quantidade de pólen aplicado, colhidas em 2005 e 2006, em A. angustifolia.

Table 3 - Mean total number of pine nuts (fully filled + hollow) yielded by pine cones subjected to controlled and open pollination, with varying amounts of pollen being applied, harvested in 2005 and 2006, in A. angustifolia.

\begin{tabular}{lc}
\hline Ano da polinização & $\begin{array}{c}\mathrm{N}^{\circ} \text { total de pinhões } \\
\text { (cheios }+ \text { chochos) }\end{array}$ \\
\hline 2003 & $142,1 \mathrm{a}$ \\
2004 & $106,5 \mathrm{~b}$ \\
\hline Tratamento & $142,1 \mathrm{a}$ \\
\hline Polinização aberta (testemunhas) & $104,6 \mathrm{~b}$ \\
$\begin{array}{l}\text { Polinização controlada com única } \\
\text { polinização }\end{array}$ & $126,1 \mathrm{ab}$ \\
$\begin{array}{l}\text { Polinização controlada com } \\
\text { excesso de pólen }\end{array}$ & $124,4 \mathrm{ab}$ \\
\hline Pinhas isoladas sem polinização & 21,9 \\
\hline CV. (\%) & \\
\hline
\end{tabular}

Médias não seguidas de mesma letra minúscula na coluna diferem significativamente pelo Teste de Tukey, em nível de $1 \%$ de probabilidade de erro.

Means not followed by the same small letter in a column differ significantly by the Tukey test, at the 1\% error probability level.

Tabela 4 - Porcentagem média de pinhões (cheios e chochos), de pinhas de polinização controlada e aberta com variação na quantidade de pólen aplicado, colhidas em 2005 e 2006, em A. angustifolia.

Table 4 - Mean percentage of pine nuts (fully filled + hollow) yielded by pine cones subjected to controlled and open pollination with varying amounts of pollen being applied, harvested in 2005 and 2006, in A. angustifolia.

\begin{tabular}{|c|c|c|c|c|}
\hline \multirow{3}{*}{ Tratamentos } & \multicolumn{2}{|c|}{ Pinhões cheios $(\%)$} & \multicolumn{2}{|c|}{ Pinhões chochos $(\%)$} \\
\hline & \multicolumn{2}{|c|}{ Ano da polinização } & \multicolumn{2}{|c|}{ Ano da polinização } \\
\hline & 2003 & 2004 & 2003 & 2004 \\
\hline Polinização aberta (testemunhas) & $42,7 \mathrm{a}$ & $31,0 \mathrm{ab}$ & $52,8 \mathrm{c}$ & $69,4 \mathrm{ab}$ \\
\hline Polinização controlada com única polinização & $36,0 \mathrm{~b}$ & $27,6 \mathrm{~b}$ & $64,0 \mathrm{~b}$ & $72,4 \mathrm{ab}$ \\
\hline Polinização controlada com excesso de pólen & $36,2 \mathrm{~b}$ & $36,4 \mathrm{a}$ & $63,8 \mathrm{~b}$ & $64,8 \mathrm{ab}$ \\
\hline Pinhas isoladas sem polinização & $0,0 \mathrm{c}$ & $0,0 \mathrm{c}$ & $100,0 \mathrm{a}$ & $100,0 \mathrm{a}$ \\
\hline C V $(\%)$ & \multicolumn{2}{|c|}{18,4} & \multicolumn{2}{|c|}{6,6} \\
\hline
\end{tabular}

Médias não seguidas de mesma letra maiúscula na linha e mesma letra minúscula na coluna diferem significativamente pelo Teste de Tukey, em nível de $1 \%$ de probabilidade de erro.

Means not followed by the same capital letter in a row and same small letter in a column differ significantly by the Tukey test, at the $1 \%$ error probability level.

Cerne, Lavras, v. 18, n. 2, p. 247-255, abr./jun. 2012 
A porcentagem de pinhões cheios com relação ao tratamento de polinização resultou em diferenças entre os anos apenas para o tratamento com polinização controlada com uma única polinização, sendo maior para o ano de 2003. No ano de 2003, a maior produtividade foi obtida nas pinhas testemunhas, seguida pelos tratamentos de polinização controlada com ou sem excesso de pólen, já, no ano de 2004, as pinhas testemunhas não diferiram do tratamento com excesso de pólen.

A polinização controlada com excesso de pólen somente foi positiva em relação ao número de pinhões produzidos em 2004, sendo que, em 2003, a utilização desse tratamento foi semelhante à polinização controlada sem excesso de pólen.

A possibilidade de aumento na produtividade deve estar mais relacionada ao momento da polinização (receptividade do ginostróbilo) e as condições ambientais do que propriamente na quantidade de pólen disponível, pois o ginostróbilo produz um número definido de óvulos que limita a produção de sementes.

A porcentagem de pinhões chochos foi significativamente diferente entre os anos para as testemunhas e para as pinhas de polinização controlada com única polinização, com maior número de pinhões chochos no ano de 2004 (Tabela 4). Vários fatores podem ter contribuído para que tanto pinhas testemunhas como tratadas apresentassem mais pinhões chochos em 2004 do que em 2003, como condições ambientais adversas nos meses de polinização e a capacidade produtiva menor das pinhas em 2004.

$\mathrm{O}$ tratamento com pinhas isoladas sem polinização foi conduzido para indicar se o isolamento utilizado nas polinizações controladas era adequado, os resultados demonstram a efetividade do isolamento plástico para impedir a entrada de pólen, com $100 \%$ de pinhões chochos.

Os valores de pinhões chochos estão bem acima daqueles citados por Mantovani et al. (2004), com uma porcentagem de 1,6\% de pinhões chochos para pinhas que se encontravam numa população natural preservada há mais de 45 anos. Resultado da menor disponibilidade de pólen nas pinhas testemunhas e tratadas.

\subsection{Efeito da época de polinização e do estádio de desenvolvimento do ginostróbilo sobre o número de pinhões produzidos por pinha}

O número total de pinhões por pinha indica semelhança na capacidade produtiva entre as plantas matrizes, mas diferenças entre as pinhas utilizadas nos diferentes tratamentos. A utilização de pinhas de ramos secundários novamente pode ter causado essa diferença, já que a capacidade produtiva total da pinha não foi afetada pelos tratamentos de polinização, como discutido anteriormente.

Para o ano de 2004, os resultados com polinizações em diferentes estádios de desenvolvimento do ginostróbilo, demonstraram que o número total de pinhões por pinha foi semelhante nas pinhas utilizadas nos quatro tratamentos. Houve diferenças estatísticas entre os tratamentos para a porcentagem de pinhões cheios, com maior média no tratamento com o ginostróbilo aberto ( $>$ de $40 \mathrm{~mm}$ de diâmetro) e menor no tratamento com o ginostróbilo aberto (30-40 mm de diâmetro). Para a porcentagem de pinhões chochos, o tratamento com os ginostróbilos abertos ( $>40$ $\mathrm{mm}$ de diâmetro), apresentaram menor média de pinhões chochos (Tabela 5).

Tabela 5-Número médio de pinhões (cheios + chochos), e porcentagem de pinhões cheios em relação aos chochos de pinhas provenientes de polinização controlada e aberta em diferentes estádios de desenvolvimento do ginostróbilo, em A. angustifolia, colhidas em 2006.

Table 5-Mean number of pine nuts (fully filled + hollow) and percentage of fully filled in relation to hollow pine nuts yielded by pine cones subjected to controlled and open pollination at different development stages of the female strobilus, in A. angustifolia, as harvested in 2006.

\begin{tabular}{lccc}
\hline Tratamento (estádio do ginostróbilo) & $\mathrm{N}^{\mathrm{o}}$ total de pinhões (cheios + chochos) & Pinhões cheios (\%) & Pinhões chochos (\%) \\
\hline Testemunhas & $131,0 \mathrm{a}$ & $30,6 \mathrm{ab}$ & $69,4 \mathrm{ab}$ \\
Abrindo (<30 mm de diâmetro) & $87,2 \mathrm{a}$ & $20,8 \mathrm{ab}$ & $79,2 \mathrm{ab}$ \\
Aberto (30 a 40 mm de diâmetro) & $92,2 \mathrm{a}$ & $7,6 \mathrm{~b}$ & $92,4 \mathrm{a}$ \\
Aberto (> 40 mm de diâmetro) & $114,0 \mathrm{a}$ & $41,4 \mathrm{a}$ & $58,6 \mathrm{~b}$ \\
\hline CV (\%) & 30,7 & 69,9 & 23,4 \\
\hline
\end{tabular}

Médias não seguidas de mesma letra minúscula na coluna diferem significativamente pelo Teste de Tukey, em nível de $5 \%$ de probabilidade de erro.

Means not followed by the same small letter in a column differ significantly by the Tukey test, at the 5\% error probability level.

Cerne, Lavras, v. 18, n. 2, p. 247-255, abr./jun. 2012 
Os resultados obtidos nos anos de 2005 e 2006, em diferentes estádios de desenvolvimento do ginostróbilo indicam estádios mais tardios de desenvolvimento (ginostróbilo com + de $30 \mathrm{~mm}$ de diâmetro) como o período mais adequado para a polinização controlada com uma única aplicação de pólen. A maior produtividade nesse estádio pode ser decorrente do maior tamanho das folhas modificadas que facilitam a permanência dos grãos de pólen no local e a entrada do tubo polínico entre as folhas do ginostróbilos e a fatores fisiológicos como a receptividade do ginostróbilo, aumentando a sua aptidão para a produção de sementes.

Adeterminação do estádio adequado do ginostróbilo, para o isolamento e receptividade para a polinização, são os pontos críticos que devem ser considerados na polinização suplementar (MARTINS et al., 1981).

A maior receptividade dos ginostróbilos em estádios mais avançados pode afetar a produtividade entre os anos, pois variações no período de polinização, com a liberação de pólen mais concentrada no início do período de polinização, quando os ginostróbilos ainda estão pequenos podem afetar negativamente a produtividade, no entanto, pode favorecer aquelas plantas femininas que apresentam precocidade na abertura dos ginostróbilos.

Há variação na dispersão do pólen entre os anos, sendo que a mesma está relacionada com as condições de pluviosidade e umidade. Nos anos mais secos, a dispersão tende a ser mais rápida, diminuindo o período de polinização e concentrando a disponibilidade de pólen em poucas semanas e, em anos mais úmidos, a tendência é de um período de polinização mais longo, podendo chegar até a três meses (SOUSA, 2000).
A umidade é outro fator fundamental para a abertura dos microesporângios e a liberação do pólen. Observa-se que em dias de sol e com vento ocorre uma nuvem de pólen, nos dias chuvosos a alta umidade e a falta de altas temperaturas impedem a abertura dos microesporângios e a liberação do pólen. Assim, a ocorrência de dias quentes e secos pode alterar a disponibilidade de pólen durante a época de polinização, causando diferenças na produtividade entre plantas femininas precoces e tardias, favorecendo aquelas que estiverem com os ginostróbilos em estádios mais avançados de desenvolvimento quando ocorrer uma maior concentração de pólen disponível.

\subsection{Efeito de polinizações sucessivas em ginostróbilos sobre o número de pinhões por pinha}

O número total de pinhões foi semelhante nas pinhas avaliadas. Não houve interação para a porcentagem de pinhões cheios e chochos, mas os mesmos influenciaram os resultados separadamente. Na matriz 2, apresentou-se maior produtividade em relação a matriz 1 , com maior média de pinhões cheios e menor de pinhões chochos (Tabela 6). Como as matrizes foram polinizadas no mesmo período, a característica de precocidade na abertura do ginostróbilo pode ter influenciado na diferença de produtividade, já que os tratamentos foram semelhantes entre as plantas, mas o estádio de desenvolvimento dos ginostróbilos polinizados pode ter variado.

Nos tratamentos com polinizações sucessivas, o tratamento 2 (duas polinizações consecutivas), resultou na maior média de pinhões cheios por pinha e na menor média de pinhões chochos (Tabela 6).

Tabela 6 - Porcentagem média de pinhões cheios em relação aos chochos de pinhas provenientes de polinização controlada única, dupla ou tripla, colhidas em 2005, em duas matrizes de A. angustifolia.

Table 6-Mean percentage of fully filled in relation to hollow pine nuts yielded by pine cones subjected to single, double and triple controlled pollination, harvested in 2005, in two matrix plants of A. angustifolia.

\begin{tabular}{lccc}
\hline Matriz & Total de pinhões (cheios + chochos) & Pinhões cheios (\%) & Pinhões chochos $(\%)$ \\
\hline 1 & $108 \mathrm{~b}$ & $8,1 \mathrm{~b}$ & $91,9 \mathrm{a}$ \\
2 & $126 \mathrm{a}$ & $22,3 \mathrm{a}$ & $77,6 \mathrm{~b}$ \\
\hline Tratamento & & Pinhões cheios $(\%)$ & Pinhões chochos $(\%)$ \\
\hline Polinização única & $122 \mathrm{a}$ & $8,3 \mathrm{~b}$ & $91,7 \mathrm{a}$ \\
Polinização dupla & $120 \mathrm{a}$ & $23,3 \mathrm{a}$ & $76,7 \mathrm{~b}$ \\
Polinização tripla & $107 \mathrm{~b}$ & $14,0 \mathrm{~b}$ & $86,0 \mathrm{a}$ \\
\hline CV $(\%)$ & & 38,5 & 6,9 \\
\hline
\end{tabular}

Médias não seguidas de mesma letra minúscula na coluna diferem significativamente pelo Teste de Tukey, em nível de $5 \%$ de probabilidade de erro.

Means not followed by the same small letter in a column differ significantly by the Tukey test, at the 5\% error probability level.

Cerne, Lavras, v. 18, n. 2, p. 247-255, abr./jun. 2012 
A aplicação única de pólen, durante todo o período de polinização pode ser insuficiente para a produção de pinhões, pois vários fatores como chuva ou calor excessivo podem prejudicar a capacidade de germinação do pólen. Além disso, se o pólen não for colocado em ginostróbilos receptivos na ocasião da polinização, haverá uma queda na formação de sementes. Na polinização aberta, o ginostróbilo fica exposto ao pólen que vem transportado pelo vento por um período de dois meses, assim se ocorrer uma chuva forte que retire todo o pólen armazenado sobre o ginostróbilo ainda há possibilidade de receber mais pólen durante o restante do período de polinização. A maturação dos androstróbilos nas plantas masculinas também é variável, ocorrendo plantas mais precoces, que liberam o pólen no início da época de polinização, e algumas plantas mais tardias que vão liberar o pólen mais tardiamente, isso também favorece a polinização por diferentes pais, nas pinhas produzidas por polinização aberta.

\section{CONCLUSÕES}

Os resultados obtidos com a polinização controlada em Araucaria angustifolia confirmam a possibilidade da aplicação imediata da metodologia em cruzamentos controlados, permitindo que cruzamentos, hoje impossíveis na natureza pela grande distância entre os pais, possam ocorrer.

Duas polinizações consecutivas em duas semanas, em ginostróbilos com mais de $30 \mathrm{~mm}$ de diâmetro, aumenta o número de pinhões cheios por pinha.

\section{REFERÊNCIAS}

ANSELMINI, J. I.; ZANETTE, F.; BONA, C. Fenologia reprodutiva da Araucaria angustifolia (Bert.) O. Ktze, na região de Curitiba, PR. Floresta e Ambiente, Rio de Janeiro, v. 13 , n. 1, p. 44-52, 2006.

BRIGATTI, R. A.; FERREIRA, M.; BEIG, O.; FREITAS, M. Polinização controlada em Eucalyptus urophylla: um programa desenvolvido pela Champion Papel e Celulose S.A. Silvicultura, São Paulo, v. 8, n. 28, p. 213-215, 1983.

CARVALHO, P. E. R. Espécies florestais brasileiras: recomendações silviculturais, potencialidades e uso da madeira. Colombro: Embrapa Florestas, 1994. 639 p.
FLORIANI, G. S. Debulhando pinha, semeando pinhão: propostas de uso e conservação para a araucária. Revista Brasileira de Agroecologia, Porto Alegre, v. 2, n. 1, p. 18031806, 2007.

INSTITUTO DE PESQUISAS E ESTUDOS FLORESTAIS. Produção de híbridos de Eucalyptus spp através da polinização controlada. Piracicaba, 1977. 4 p.

KRAMER, P. J.; KOZLOWSKI, T. Physiology of woody plants. New York: Academic, 1979. 811 p.

MANTOVANI, A.; MORELLATO, P. C.; REIS, M. S. Fenologia reprodutiva e produção de sementes em Araucaria angustifolia (Bert.) O. Kuntze. Revista Brasileira de Botânica, São Paulo, v. 27, n. 4, p. 787-796, 2004.

MARTINS, M. E.; PRERA, L. E. H.; KAGEYAMA, P. Y. Manejo de pólen de Pinus para fins de melhoramento genético. Piracicaba: IPEF, 1981. 7 p. (Circular técnica, 128).

\section{MICHIGAN STATE UNIVERSITY. Microcomputer} statistical program. East Lansing, 1991. 400 p.

PIRES, P. T. L. Alternativas políticas e jurídicas para a gestão das florestas de araucária no Estado do Paraná. 2003. 207 f. Tese (Doutorado em Ciências Florestais) Universidade Federal do Paraná, Curitiba, 2003.

POWELL, G. R. Initiation and development of subterminal buds in Abies balsamea. Canadian Journal of Forest Research, Ottawa, v. 7, p. 258-262, 1977.

SMITH, W. K.; HINCKLEY, T. M. Resource physiology of conifers: acquisition, allocation and utilization. San Diego: Academic, 1995. 397 p.

SOUSA, V. A. Population genetic studies in Araucaria angustifolia (Bert.) O. Ktze. 2000. $161 \mathrm{f}$. Thesis (Ph.D. in Forest Science) - Goettingen University, Gottingen, 2000.

TESDORFF, H. Experimentos de cruzamentos com Araucaria araucana (Molina) Koch e Araucaria angustifolia (Bert.) O. Ktze. Jornal de Genética Florestal e Melhoramento Florestal, Piracicaba, v. 5, p. 79-82, 1956. 